\title{
Lipoprotein(a) hyperlipidemia as cardiovascular risk factor: pathophysiological aspects
}

\author{
Gerd Schmitz • Evelyn Orsó
}

Published online: 24 February 2015

The Author(s) 2015 This article is published with open access at Springerlink.com

\begin{abstract}
Lipoprotein (a) [Lp(a)] is a modified LDL particle with an additional apolipoprotein [apo(a)] protein covalently attached by a thioester bond. Multiple isoforms of apo(a) exist that are genetically determined by differences in the number of Kringle-IV type-2 repeats encoded by the LPA gene. Elevated plasma $\mathrm{Lp}(\mathrm{a})$ is an independent risk factor for cardiovascular disease.

The phenotypic diversity of familial $\mathrm{Lp}(\mathrm{a})$ hyperlipidemia [Lp(a)-HLP] and familial hypercholesterolemia $[\mathrm{FH}]$, as defined risks with genetic background, and their frequent co-incidence with additional cardiovascular risk factors require a critical revision of the current diagnostic and therapeutic recommendations established for isolated familial Lp(a)-HLP or FH in combination with elevated Lp(a) levels.

Lp(a) assays still suffer from poor standardization, comparability and particle variation. Further evaluation of the current biomarkers and establishment of novel comorbidity biomarkers are necessary for extended risk assessment of cardiovascular disease in FH or Lp(a)-HLP and to better understand the pathophysiology and to improve patient stratification of the $\mathrm{Lp}(\mathrm{a})$ syndrome complex.

$\mathrm{Lp}$ (a) promotes vascular remodeling, increased lesion progression and intima media thickening through induction of M1-macrophages, antiangiogenic effects (e.g. vasa vasorum) with secretion of the antiangiogenic chemokine CXCL10 (IP10) and CXCR3 mediated activation of Th1and NK-cells.
\end{abstract}

Prof. G. Schmitz, MD $(\bowtie) \cdot$ E. Orsó

Institute for Laboratory Medicine and Transfusion Medicine,

University Hospital of Regensburg,

Franz-Josef-Strauss-Allee 11,

93053 Regensburg, Germany

e-mail: gerd.schmitz@klinik.uni-regensburg.de
In addition inhibition of serine proteases causing disturbances of thrombosis/ hemostasis/ fibrinolysis, TGF $\beta$ activation and acute phase response (e.g. CRP, anti-PL antibodies) are major features of Lp(a) pathology. Anti-PL antibodies (EO6 epitope) also bind to oxidized Lp(a).

Lipoprotein apheresis is used to reduce circulating lipoproteins in patients with severe FH and/or Lp(a)-HLP, particularly with multiple cardiovascular risks who are intolerant or insufficiently responsive to lipid-lowering drugs.

Keywords Lipoprotein(a) C Cardiovascular risk · Pathophysiology $\cdot$ Biomarker

Zusammenfassung Lipoprotein (a) [Lp(a)] ist ein modifizierter LDL-Partikel assoziiert mit Apolipoprotein [Apo(a)], as an den LDL-Partikel durch eine kovalente Thioesterbindung gebunden ist. Es sind mehrere genetisch determinierte Apo(a)-Isoformen bekannt, die sich durch die Anzahl der Typ-2 Kringle-IV Domänen unterscheiden.

Eine erhöhte Lp(a) Plasmakonzentration ist ein unabhängiger Risikofaktor für kardiovaskuläre Erkrankungen.

Aufgrund der phänotypischen Heterogenität der familiären $L p(a)-H y p e r l i p o p r o t e i n a ̈ m i e ~[L p(a)-H L P]$ und der familiären Hypercholesterinämie [FH], als genetischdefinierte Risiken, sowie deren häufige Koinzidenz mit weiteren kardiovaskulären Risikofaktoren, müssen die aktuellen diagnostischen und therapeutischen Empfehlungen nochmals überprüft werden, die für die isolierte Lp(a)-HLP oder FH ohne erhöhtes Lp(a), bzw. deren Kombination mit erhöhten Lp(a)-Spiegeln etabliert wurden.

Die derzeit am Markt befindlichen Lp(a)-Bestimmungsmethoden sind ungenügend standardisiert, nicht exakt vergleichbar und berücksichtigen nicht die Variabilität der Partikelgröße. Die aktuellen Biomarker erfordern eine Ergänzung und Validierung durch neue Komorbiditäts- 
Marker, die die Pathogenese der kardiovaskulären Risikofaktoren bei FH oder Lp(a)-HLP präziser beschreiben und eine bessere Stratifizierung von Patienten mit Lp(a)-Syndromen ermöglichen.

$\mathrm{Lp}$ (a) fördert die vaskuläre Remodellierung, die zu einer Progression der atherosklerotischen Läsion und Verdickung der vaskulären Intima durch Induktion von M1-Makrophagen führen, sowie damit assoziierte antiangiogenetische Prozesse (z. B. Vasa vasorum) wie die Sekretion des anti-angiogenischen Chemokins CXCL10 (IP10) und des Th1- und NK-Zellen aktivierenden Chemokins CXCR3.

Darüber hinaus hemmt Lp(a) verschiedene Serinproteasen, die Störungen im Thrombose/Hämostase/Fibrinolyse-System verursachen können. Weitere pathogene Eigenschaften der $L p(a)$ sind die TGFb-Aktivierung und die Induktion einer Akute-Phase-Response Reaktion (z. B. CRP-Erhöhung, Synthese von Anti-PL-Antikörpern). AntiPL-Antikörper (EO6 Epitope) binden bevorzugt an oxidierte $\operatorname{Lp}(\mathrm{a})$.

Die therapeutische Lipoprotein-Apherese wird bei schwerwiegenden FH- und/oder Lp(a)-HPL-Fällen zur Reduktion der zirkulierenden Lipoproteinkonzentration eingesetzt. Insbesondere Patienten mit multiplen Risikofaktoren, mit Medikamentenunverträglichkeit von Lipidsenkern oder mit unzureichender Lipidsenkung sollten mit der Lipidapherese behandelt werden.

Schlüsselwörter Lipoprotein(a) · Kardiovaskuläres Risiko · Pathophysiologie · Biomarker

\section{Introduction}

Atherosclerotic cardiovascular disease (CVD) is one of the major factors for morbidity and mortality in Western countries. Established risk factors for CVD, include elevated plasma concentration of lipoprotein(a) (Lp(a)), high plasma concentration of low density lipoprotein (LDL), low plasma concentration of high density lipoprotein (HDL), hypertension, diabetes, obesity, metabolic syndrome and smoking among others [1-3 and references therein]. Since the atherogenic process leading to CVD begins in childhood and is progressive throughout the life span [2], screening for risk factors, appropriate patient stratification and therapeutic management are essential. Lp(a)-hyperlipidemia (Lp(a)HLP) has been reported as an independent risk factor for CVD [4-6 and references therein]. Lp(a)-HLP occurs either alone, or in combination with other genetic backgrounds for hyperlipidemia and CVD risk, such as familial hypercholesterolemia $(\mathrm{FH})$ or apolipoprotein E4-allele, therefore early recognition of diverse co-morbidities is essentially required [3]. However, despite of considerable efforts, the precise pathophysiological mechanisms, how $\mathrm{Lp}$ (a) contributes to atherogenesis, are not fully elucidated.

\section{Lipoprotein(a) hyperlipidemia (Lp(a)-HLP)}

Lipoprotein(a) [Lp(a)], first described by Berg in 1963 [7], is composed of apolipoprotein (a) (apo(a)), covalently attached to apolipoprotein B-100 (apoB-100) by a disulfide bond on kringle-IV type- $9\left(\mathrm{KIV}_{9}\right)$ in close proximity to the LDL receptor binding site of apoB-100 [8]. The apo(a) gene (LPA) is a major determinant of the plasma concentration of Lp(a), and several genetic LPA-variants have been described, including variations in the kringle region-coding repeats, which account for the size polymorphism of apo(a), diverse single nucleotide polymorphisms (SNPs) and other variants in the promoter of LPA [9-11]. There is an inverse relationship between the number of kringle repeats of apo(a) and the concentration of $\mathrm{Lp}$ (a) in plasma (reviewed in 5). The plasma levels of $\mathrm{Lp}$ (a) show significant diversity in ethnical groups (e.g. African-Americans have higher plasma $\mathrm{Lp}$ (a) concentrations than Caucasians), and in individuals carrying apo(a) even of the same size polymorphism [10, 11], but the underlying mechanisms have yet to be identified. The latter issue implies the possibility of the presence of additional factors for CVD risk of $L p(a)$.

\section{Measurement of $\mathrm{Lp}(\mathrm{a})$ in plasma}

Quantitative determination of $\mathrm{Lp}(\mathrm{a})$ in human plasma (or serum) is currently a standard approach of clinical laboratories. In contrast to first generation immunoassays, recognizing kringle-IV type-2 $\left(\mathrm{KIV}_{2}\right)$, current diagnostic antibodies bind to $\mathrm{KIV}_{9}$, and this binding site is more stable than $\mathrm{KIV}_{2}$, even in frozen samples [12]. Taking into account that the molecular weight of apo(a), depending on the genetic polymorphisms of apo(a), varies between 275 and $800 \mathrm{kDa}$ in different individuals [5], plasma levels of $L p(a)$ expressed in $\mathrm{mg} / \mathrm{L}$ or $\mathrm{mmol} / \mathrm{L}$ may lead to confusion. At present, there is no commercial $\mathrm{Lp}(\mathrm{a})$ assay that is completely insensitive to the variability in $\mathrm{Lp}(\mathrm{a})$ particle mass, and $\mathrm{Lp}(\mathrm{a})$ mass refers to the entire mass of the whole particle, including lipids, proteins and carbohydrates [13]. In their recent paper McConnell and co-workers claim for novel mass-insensitive Lp(a) assays, since lipoprotein "particle number" seems to be superior to component-based metrics for CVD risk prediction [13]. In a very recent work the simultaneous quantitation and size characterization of apo(a) by ultraperformance liquid chromatography/mass spectrometry was reported [14]. The latter may be an initial step for development of mass-insensitive $\mathrm{Lp}(\mathrm{a})$ assays in the future. 


\section{Lipoprotein(a) in atherogenesis}

The kringle domains of apo(a) show high degree of homology to the kringle-IV and kringle- $\mathrm{V}$ of plasminogen, the zymogen for the fibrinolytic serine protease plasmin, and the atherogenic potential of $L p(a)$ is partially attributed to this structural homology [reviewed in 15]. The kringle structure of $\mathrm{Lp}(\mathrm{a})$ and plasminogen differs in one single amino acid (R560S), and it protects apo(a) from enzymatic cleavage by plasminogen activators, such as tissue-type plasminogen activator (t-PA) and urokinase plasminogen activators (u-PA) [9, 15]. In addition to this molecular mimicry of $L p(a)$ to plasminogen, there are further mechanisms contributing to the role of $\mathrm{Lp}(\mathrm{a})$ in atherogenesis and development of CVD: (1) Lp(a) is able to bind to the tissue factor pathway inhibitor (TFPI), which is responsible for the prothrombotic properties of $\mathrm{Lp}$ (a) [16]. (2) Lp(a) can dock on certain lipoprotein receptors, including LDL receptor (LDLR), LDLR-related protein(s) and very low density lipoprotein (VLDL) receptor, leading to $\mathrm{Lp}(\mathrm{a})$ internalization, although to a lesser extent than the natural ligands of these receptors [17]. (3) Lp(a) can be entrapped by matricellular proteins (e.g. laminin, thrombospondin, tetranectin, fibrinogen/fibrin, glycosaminoglycans, fibronectin), leading to retention of $L p(a)$ and recruitment of monocytes in atherosclerotic lesions $[15,18]$. (4) $\mathrm{Lp}(\mathrm{a})$ leads to endothelial barrier dysfunction through dysregulated myosin light chains via a Rho/Rho-kinase mediated signalling, and in this process a strong lysine-binding site in kringle-IV type$10\left(\mathrm{KIV}_{10}\right)$ of apo(a) plays an essential role [19]. (5) Lp(a) modulates inflammatory responses and abolishes recruitment of neutrophils [20]. (6) Lp(a) promotes the differentiation of pro-inflammatory, M1-type macrophages, that secrete CXCL10 (IP10) chemokine leading to activation of T-helper-1 (Th1) lymphocytes and natural killer (NK) cells [21-23]. The chemokine CXCL10 is increasingly regarded as a potent inhibitor of angiogenesis, that may affect vasa vasorum angiogenesis. Thus $\mathrm{Lp}(\mathrm{a})$ may perpetuate vascular remodelling by blocking myoepithelial organization of newly formed vascular tubes. The importance of CXCL10 in vascular disease progression is further supported by the expanding literature.

In recent years Witztum and co-workers have demonstrated in consecutive papers that a substantial portion of pro-inflammatory and pro-atherogenic oxidized phospholipids, produced in response to reactive oxygen species (ROS), is present on apo(a) and $L p(a)$ [24 and references therein]. By using epitope-specific monoclonal antibodies (particularly E06, but also others), recognizing oxidized but not native phospholipids (i.e. oxidation-specific epitopes, OSEs), they have found plasma levels of oxidized phospholipids correlating with concentrations of $\mathrm{Lp}(\mathrm{a})$ in plasma, apo(a) size polymorphism and CVD [24]. The E06 antibody was able to inhibit the recognition and uptake of oxidized phospholipids and apoptotic cells by macrophage scavenger receptors, and reduce the progression of CVD in an atherosclerosis-susceptible mouse model [reviewed in 24]. The innate immune system recognizes OSEs as danger-associated molecular patterns (DAMPs), and uses innate pattern recognition receptors and soluble factors for their clearance [25 and references therein]. The E06 immunoreactivity of apo(a), indicating pro-inflammatory oxidized phospholipids accessible to DAMPs, was found to be strongly influenced by $\mathrm{KIV}_{10}$, which may explain the atherogenic potential of Lp(a) [26]. In addition, Lp(a) and oxidized LDL (oxLDL) both bind monocyte chemoattractant protein-1 (MCP-1/ CCL2), a major chemokine in induction and progression of vascular inflammation, and oxidized phospholipids were shown to be major determinants for MCP-1 binding [27]. Based on the critical role of oxidized phospholipids and OSEs in Lp(a)-associated atherogenesis, development of atheroprotective vaccines recognizing and masking OSEs may be beneficial to reduce CVD risk.

The levels of oxidized phospholipids are modified by the activity of lipoprotein-associated phospholipase A2 (Lp-PLA, former platelet activating factor acetylhydrolase, PAFAH), which converts oxidized phospholipids to oxidized fatty acids and lysophosphatidylcholine (lysoPC) $[24,28]$. Both lipid species have been shown to be proinflammatory and pro-atherogenic in vitro. Stronger association of $\mathrm{Lp}-\mathrm{PLA}_{2}$ was found with $\mathrm{Lp}(\mathrm{a})$ as compared to LDL [28].

In a recent study release of phosphatidylcholine-containing oxidized phospholipids and oxidized cholesteryl esters, such as oxidized derivatives from cholesteryl linoleate and cholesteryl arachidonate, was demonstrated downstream from obstructive plaques in human, and these bioactive lipids were captured during percutaneous interventions [29]. This study clearly shows the presence of critical pro-inflammatory and pro-atherogenic lipids in the local microcirculation in human arterial tissue.

Taken together, $\mathrm{Lp}(\mathrm{a})$ exerts its pro-atherogenic role via multiple mechanisms, and the precise compositional analysis of $\mathrm{Lp}$ (a) particles contributes to a sophisticated evaluation of $\mathrm{Lp}(\mathrm{a})$-associated CVD risk.

\section{Lp(a)-lowering therapy}

Currently it is unclear if lowering $\mathrm{Lp}(\mathrm{a})$ levels will also reduce the risk of CVD, since the first specific $\mathrm{Lp}(\mathrm{a})$ decreasing compound(s) have recently been developed and clinical outcome data have not yet been published [6].

Several previous pharmacological approaches have shown Lp(a)-lowering effects (e.g. nicotinic acid, oestrogen, eprotirome, antisense apoB-100, inhibitors of choles- 
teryl ester transfer protein (CETP), monoclonal antibodies against apo(a) or proprotein convertase subtilisin/kexin type-9 (PCSK9)), but the decrease of plasma Lp(a)-levels in $L p(a)-H L P$ are/were insufficient without major adverse effects [reviewed in 6].

Prevention and/or adequate treatment of additional CVD risks such as smoking, obesity, hypertension, diabetes, alcohol consumption, although they are important interventions, have no major impact in the management of $L p(a)-$ HLP $[1,2]$.

The long-time use of $\mathrm{Lp}$ (a) apheresis in combination with maximal tolerated doses of lipid-lowering drugs reduced the plasma concentrations of $L p(a)$ by over $70 \%$, parallel with a decrease of the mean annual rate of major adverse coronary events, as a measure of outcome, in a recent longitudinal, multicenter, cohort study [30].

The recommendations of the HEART-UK Working Group indicates that patients with progressive CVD, and with plasma concentrations of $\mathrm{Lp}(\mathrm{a})$ above $60 \mathrm{mg} / \mathrm{dL}$, and plasma LDL cholesterol above $3.2 \mathrm{mmol} / \mathrm{L}$ (despite of maximal lipid-lowering drug therapy) should be considered for LDL apheresis [31]. Although LDL apheresis is able to provide reduced plasma concentrations of $L p(a)$, based on the structural similarities of LDL and $\mathrm{Lp}$ (a) particles, patients with isolated $\mathrm{Lp}(\mathrm{a})$-HLP should rather be treated by $\mathrm{Lp}(\mathrm{a})$ apheresis [reviewed in 32].

The lack of clear guidance for the indication of $L p(a)$ apheresis treatment requires further efforts, but most apheresis centers work currently with the criteria of (i) $60 \mathrm{mg} /$ dL Lp(a) in plasma as cut-off, and (ii) history of advanced and/or progressive CVD, and alternatively (iii) presence of additional risk factors for CVD that accelerate the course of disease [3].

Further studies are required, however, (a) to optimize management in order to reduce CVD risk associated with Lp(a)-HLP, and (b) to evaluate what other intermediate and/ or high risk groups may benefit from $\mathrm{Lp}(\mathrm{a})$ screening [33].

\section{Conclusion}

Despite of emerging data from clinical and experimental studies our current knowledge about the impact of $L p(a)$ HLP in development of atherogenic CVD is still insufficient. A critical reappraisal of the current diagnostic and screening criteria as well as therapeutic recommendations is required. Further evaluation of recent, and establishment of novel biomarkers are necessary for appropriate risk assessment of CVD in Lp(a)-HLP. Novel mass-insensitive Lp(a) assays should be developed for precise laboratory screening of elevated plasma $\mathrm{Lp}(\mathrm{a})$, and follow-up of therapeutic effects in Lp(a)-HLP.
Acknowledgement This work was supported by the 7th Framework Program of the European Community (FP7/2007-2013) under grant agreement $n^{\circ} 202272$, IP-Project LipidomicNet (Lipid droplets as dynamic organelles of fat deposition and release: translational research towards human disease).

Conflict of interest There is no personal or financial conflict of interest to disclose for the authors.

Open Access This article is distributed under the terms of the Creative Commons Attribution License which permits any use, distribution, and reproduction in any medium, provided the original author(s) and the source are credited.

\section{References}

1. Daniels SR, Greer FR, The Committee on Nutrition (2008) Lipid screening and cardiovascular health in childhood. Pediatrics 122:198-208.

2. Berenson GS, Srinivasan SR, Bao W, Newman WP III, Tracy RE, Wattigney WA (1998) Association between multiple cardiovascular risk factors and the early development of atherosclerosis. Bogalusa Heart Study. N Engl J Med 338:1650-1656.

3. Orsó E, Ahrens N, Kilalić D, Schmitz G (2009) Familial hypercholesterolemia and lipoprotein(a) hyperlipidemia as independent and combined cardiovascular risk factors. Atheroscler Suppl 10:74-78.

4. Lamon-Fava S, Diffenderfer MR, Marcovina SM (2014) Lipoprotein(a) metabolism. Curr Opin Lipidol 25:189-193.

5. Durrington PN, Schofield JD, Siahmansur T, Soran H (2014) Lipoprotein (a): gene genie. Curr Opin Lipidol 25:289-296.

6. Bos S, Yayha R, Roeters van Lennep JE (2014) Latest developments in the treatment of lipoprotein (a). Curr Opin Lipidol 25:452-460.

7. Berg K (1963) A new serum type system in man - the Lp system. Acta Pathol Microbiol Scand 59:369-382.

8. Utermann G, Weber W (1983) Protein composition of Lp(a) lipoprotein from human plasma. FEBS Lett 154:357-361.

9. Utermann G (1998) The mysteries of lipoprotein(a). Science (Washington DC) 246:904-910.

10. Rubin J, Kim HJ, Pearson TA, Holleran S, Berglund L, Ramakrishnan R (2008) The apolipoprotein(a) gene: linkage disequilibria at three loci differs in African Americans and Caucasians. Atherosclerosis 201:138-147.

11. Chretien JP, Coresh J, Berthier-Schaad Y, Kao WH, Fink NE, Klag MJ, Marcovina SM, Giaculli F, Smith MW (2006) Three singlenucleotide polymorphisms in LPA account for most of the increase in lipoprotein(a) level elevation in African Americans compared with European Americans. J Med Genet 43:917-923.

12. Scanu AM, Edelstein C (1997) Learning about the structure and biology of human lipoprotein a. through dissection by enzymes of the elastase family: facts and speculations. J Lipid Res 38:2193-2206.

13. McConnell JP, Guadagno PA, Dayspring TD, Hoefner DM, Thiselton DL, Warnich GL, Harris WS (2014) Lipoprotein(a) mass: a massively misunderstood metric. J Clin Lipidol 8:550-553.

14. Lassman ME, McLaughlin TM, Zhou H, Pan Y, Marcovina SM, Laterza O, Roddy TP (2014) Simultaneous quantitation and size characterization of apolipoprotein(a) by ultra-performance liquid chromatography/mass spectrometry. Rapid Commun Mass Spectrom 28:1101-1106. 
15. Leischik R, Dworrak B (2006) Lipoprotein(a): Bedeutung für das fibrinolytische System und thromboembolische Komplikationen. Herz 31:144-152.

16. Caplice NM, Panetta C, Peterson TE, Kleppe LS, Mueske CS, Kostner GM, Broze GJ Jr, Simari RD (2001) Lipoprotein(a) binds and inactivates tissue factor pathway inhibitor: a novel link between lipoproteins and thrombosis. Blood 98:2980-2987.

17. Argraves KM, Kozarsky KF, Fallon JT, Harpel PC, Strickland DK (1997) The atherogenic lipoprotein Lp(a) is internalized and degraded in a process mediated by the VLDL receptor. J Clin Invest 100:2170-2181

18. D'Angelo A, Geroldi D, Hancock MA, Valtulina V, Cornaglia AI, Spencer CA, Emanuele E, Calligaro A, Koschinsky ML, Speziale P, Visai L (2005) The apolipoprotein(a) component of lipoprotein(a) mediates binding to laminin: contribution to selective retention of lipoprotein(a) in atherosclerotic lesions. Biochim Biophys Acta 1687:1-10.

19. Cho T, Jung Y, Koschinsky ML (2008) Apolipoprotein(a), through its strong lysine-binding site in KIV10, mediates increased endothelial cell contraction and permeability via a Rho/Rho kinase/ MYPT1-dependent pathway. J Biol Chem 283:30503-30512.

20. Hoover-Plow J, Hart E, Gong Y, Shchurin A, Schneeman T (2009) A physiological function for apolipoprotein(a): a natural regulator of the inflammatory response. Exp Biol Med 234:28-34.

21. Mantovani A, Sica A, Sozzani S, Allavena P, Vecchi A, Locati M (2004) The chemokine system in diverse forms of macrophage activation and polarization. Trends Immunol 25:677-686.

22. Buechler C, Ullrich H, Ritter M, Porsch-Oezcueruemez M, Lackner KJ, Barlage S, Friedrich SO, Kostner GM, Schmitz G (2001) Lipoprotein(a) up-regulates the expression of the plasminogen activator inhibitor-2 in human monocytes. Blood 97:981-986.

23. Buechler C, Ullrich H, Aslanidis C, Bared SM, Lingenhel A, Ritter M, Schmitz G (2003) Lipoprotein(a) down-regulates lisosomal acid lipase and induces interleukin-6 in human blood monocytes. Biochim Biophys Acta 1642:25-31.

24. Tsimikas S, Witztum JL (2008) The role of oxidized phospholipids in mediating lipoprotein(a) atherogenicity. Curr Opin Lipidol 19:369-377.
25. Miller YI, Tsimikas S (2013) Oxidation-specific epitopes as targets for biotheranostic applications in humans: biomarkers, molecular imaging and therapeutics. Curr Opin Lipidol 24:426-437.

26. Leibundgut G, Scipione C, Yin H, Schneider M, Boffa MB, Green S, Yang X, Dennis E, Witztum JL, Koschinsky ML, Tsimikas S (2013) Determinants of binding of oxidized phospholipids on apolipoprotein (a) and lipoprotein (a). J Lipid Res 54:2815-2830.

27. Wiesner P, Tafelmeier M, Chittka D, Choi SH, Zhang L, Byun YS, Almazan F, Yang X, Iqbal N, Chowdhury P, Maisel A, Witztum JL, Handel TM, Tsimikas S, Miller YI (2013) MCP-1 binds to oxidized LDL and is carried by lipoprotein(a) in human plasma. J Lipid Res 54:1877-1883.

28. Blencowe C, Hermetter A, Kostner GM et al (1995) Enhanced association of platelet-activating factor acetylhydrolase with lipoprotein(a) in comparison with low density lipoprotein. J Biol Chem 270:31151-31157.

29. Ravandi A, Leibundgut G, Hung MY, Patel M, Hutchins PM, Murphy RC, Prasad A, Mahmud E, Miller YI, Dennis EA, Witztum JL, Tsimikas S (2014) Release and capture of bioactive oxidized phospholipids and oxidized cholesteryl esters during percutaneous coronary and peripheral arterial interventions in humans. J Am Coll Cardiol 63:1961-1971.

30. Jaeger BR, Richter Y, Nagel D, Heigl F, Vogt A, Roeseler E, Parhofer K, Ramlow W, Koch M, Utermann G, Labarrere CA, Seidel D, Group of Clinical Investigators (2009) Longitudinal cohort study on the effectiveness of lipid apheresis treatment to reduce high lipoprotein(a) levels and prevent major adverse coronary events. Nat Clin Pract Cardiovasc Med 6:229-239.

31. Thompson GR, HEART-UK LDL Apheresis Working Group (2008) Recommendations for the use of LDL apheresis. Atherosclerosis 198:247-255.

32. Thompson GR (2010) Lipoprotein apheresis. Curr Opin Lipidol 21:487-491.

33. Jacobson TA (2013) Lipoprotein(a), cardiovascular disease, and contemporary management. Mayo Clin Proc 88:1294-1311. 